\section{NEW METALS AND NEW METHODS*}

\author{
BY DR. C. H. DESCH, F.R.S.
}

$\mathrm{T}$ HERE has been an enormous increase in the production of the most important metals, the output doubling itself in quite a short period : twelve years for copper, seventeen for pig iron, eighteen for tin, and so on. Along with this quantitative growth, the development of modern industry has brought with it remarkable qualitative changes, elements which until lately were curiosities of the laboratory rising into industrial importance. Aluminium, which seventy-five years ago had only been obtained in quantities of a few pounds, had a world production at the beginning of the War approaching a million tons, while its later development on both sides of the Atlantic has been on a very large scale. Aluminium is not one of the rare metals; it is, in fact, the most abundant of all metals in the earth's crust, but at present bauxite, a rich mineral of very local distribution, is alone used for its extraction. But elements of rare occurrence, such as tungsten, molybdenum and vanadium, now occupy, in consequence of the everincreasing demands of the engineering industries for materials of higher strength or other special properties, a key position out of all proportion to their abundance. This is largely due to the discovery that the properties of a metal may be profoundly altered by very small additions of another element, metal or non-metal. Pure iron is even softer than copper, but less than 1 per cent of carbon converts it into steel which may be made so hard as to scratch glass. This fact had been discovered empirically many centuries ago, but now that the process is better understood there are many other instances of the same kind. Copper can be made hard enough to serve as springs and even as non-sparking mining tools by adding $2 \cdot 5$ per cent of beryllium, while the soft metal lead may be strengthened, so as to offer a greater resistance to frost when used for water-pipes, by alloying with so little as 0.05 per cent of tellurium.

These and similar observations have Ied to important developments in metallurgy depending on the use of comparatively rare metals which are mostly found only in local concentrations in various parts of the earth. In a statistical table, the production of some of the minerals from which these rare elements are obtained may not seem impressive, but the access to them may be an important factor in the capacity of a country to produce machinery and other constructions into which metals enter.

The usefulness of the less common metals is, of course, not confined to small additions. The possible combinations of metals with one another are virtually infinite, and in spite of the vast amount of research and practical experience in this field, there must be many valuable combinations as yet undiscovered. The first recognition, partly accidental, that steel could be made to resist corrosion by incorporating 14 per cent or so of chromium, Ied to the development of the important class of stainless steels, while the new magnet steels, containing aluminium and nickel, and in their later forms also cobalt and copper, have brought about a revolution in the construction of electrical instruments and loud-speakers, the very high magnetic concentration which is possible with

* Paper read at the Conference on Mineral Resources and the Atlantic Charter arranged by the Division for the Social and Inter- them enabling very small permanent magnets to be used. For other purposes, such as the clutches used for holding work in milling and grinding machines, they replace electro-magnets. With these steels it is possible to realize the image of Mahomet's coffinheavy bars floating in the air in consequence of their strong magnetic repulsion.

A few of the rare metals find applications depending on their own peculiar properties. Thus tungsten, with its very high melting point of $3650^{\circ} \mathrm{C}$., has superseded all other materials for the filaments of electric lamps. The invention of the fountain-pen called for an exceedingly hard and incorrodible substance for the tips of the gold nibs, and this was found in a native alloy of osmium and iridium. Tantalum has proved specially suitable for the spinnerets used in making artificial silk, rhodium and indium for depositing in thin layers on other metals for protection against corrosion, and so on. The nonmetal selenium is used in photo-electric cells. Further uses of this kind will present themselves as the properties of the less common elements are studied more completely.

The high melting point of some of the metals has led to research in two main directions. On one hand, it has been necessary to devise means of making metals compact and strong without melting them; and on the other, to develop new materials and new techniques for operations at temperatures higher than those in ordinary metallurgical furnaces. Tungsten cannot be melted in a container of any known refractory material. The powder obtained by reducing its oxide is therefore packed into the form of bars under pressure and heated electrically until the particles cohere, and is then hammered in a special way until its strength is sufficient to allow of it being forged or drawn into wire. The same process has been applied to other metals, and a new branch of technology, known as 'powder metallurgy', has grown up. Not only the metals of high melting point, but also copper, bronze, and even the lowmelting alloys of tin, are prepared in the form of small particles and made to cohere by heat and pressure.

The method has several advantages. Small objects may be produced of accurate shape, requiring no machining, by pressing in dies, while the mass may be made completely solid or given any required degree of porosity. Such porous masses are particularly useful for bearing metals, the spongy metal holding the lubricant better than by any arrangement of grooves The method of consolidating a powder is also used in the making of carbide tools. Certain very hard compounds, especially the carbides of tungsten and titanium, which for many purposes can replace diamonds, are brittle in the mass, but if crushed and mixed with a metallic powder, mainly cobalt, and then heated until perfect union with the binding material is brought about, yield a composite mass which is excellent for tools and dies.

The chief obstacle to chemical operations at very high temperatures, $1,600^{\circ} \mathrm{C}$. or above, lies in the difficulty of finding materials for furnace construction and for containing vessels which are both strong and resistant to chemical attack at such temperatures. The ordinary fireclays become soft and are attacked by slags. A few oxides, especially alumina, magnesia, thoria, and beryllia, meet severe requirements in this field, but their refractory qualities are lessened by quite small proportions of impurity, and their preparation calls for special technique, which has been 
developed as a result of long research in the laboratory, but has as yet been little applied on a large scale. When such materials become available in quantity-and there is no difficulty in principle, although the procedure may be costly-we shall see important developments in chemistry and metallurgy at high temperatures. It is interesting to note that it is the oxides of some of the rare elements-thorium, beryllium and zirconium-which have the highest softening points among the refractory materials, so that their importance will grow with the extension of high-temperature processes.

In the heating of metals or other conductors, it is not necessary that the heat should pass through the walls of the containing vessel, as it does when a metal is melted in a crucible furnace. Modern heating by induced currents of high frequency allows the heat to be generated where it is required, that is, within the mass to be heated. This involves a less severe tax on the refractory materials, and also makes it possible to enclose the charge in an outer closed vessel which remains cold, so that the operation can be carried out in a high vacuum or in an atmosphere of some inert gas. This is not merely a laboratory device, but is used on a large scale in a number of manufacturing operations, which will become more numerous in the future. Melting in a vacuum, out of contact with furnace gases, gives a means of preparing many substances in a state of great purity and soundness, unobtainable in other ways, and is already applied to certain alloys in amounts of several tons at a time.

Many chemical reactions are made possible or are accelerated by high pressures. The autoclave has long been a familiar piece of chemical plant, but some of the processes for the production of ammonia from the air or for the hydrogenation of coal to form oils and petrol called for higher pressures than those of the usual autoclave, and recent work, especially in the United States, has shown the remarkable results which may be obtained under pressures of many thousands of atmospheres. To construct vessels to be operated at such pressures, sometimes combined with high temperatures, naturally involves entirely new engineering methods. The materials used are mainly steels, although hard carbides may have to be used for certain parts; but for the highest pressures counterbalancing stresses have to be applied by shrinking one cylinder over another or in various ways producing an internal stress opposite to that which will arise in operation. Here is another new branch of engineering of great scientific interest, extending the range of usefulness of known materials.

The substitution of one metal for another for particular purposes is not always due to inherent advantages, but is often a consequence of a policy of self-suficiency adopted by an industrial country. This motive has been very prominent in reoent years. It is natural that Germany, producing much aluminium but very little copper, should adopt the lighter metal for overhead electric power cables, but a similar replacement in the windings of motors and dynamos was purely due to conditions of blockade and could not be defended on other grounds. During the period of armament and of hostilities such substitutions have been very numerous, but the subject is too big to be entered on here. A few instances of substitution under normal conditions may be mentioned. The saving of weight by using light alloys of aluminium or magnesium in place of steel has mainly been utilized in aircraft and rolling stock construction, but it has occasionally been applied in ordinary structural work. A bridge in Pittsburgh, having been condemned as insufficiently strong for the increased traffic, was lightened by replacing the wrought iron road girders and floor by aluminium alloy. The main girders were still in good condition, and the lightening of the dead load gave the bridge a new lease of life.

The substitution of one material for another is not, as a rule, a simple matter. Metals differ not only in strength but also in elastic properties, and this difference has to be allowed for. The new Quebec Bridge was designed to take advantage of the high tensile strength of nickel steel, the designers considering that the Forth Bridge, a very stable structure, was unnecessarily heavy. The disaster of 1907, when the unfinished bridge collapsed, was due to the crumpling of the lower members, although calculation had shown that the direct load-carrying capacity was ample. It has been proposed to use alloys of aluminium on a large scale in shipbuilding, their use in small vessels having proved successful, while the particular alloys used-those with magnesium-are highly resistant to corrosion by sea-water. In changing from steel to light alloy, however, it would not be enough to calculate the dimensions of each member to give a strength equal to that in a steel ship. The hull would float too high in the water, and problems of stiffness would arise from the very different elastic properties; to build a successful vessel the design would have to be new from the beginning.

So, when the hard carbide steels were introduced to take the place of tool steels for very heavy work or large output, allowing cuts to be made on a lathe at much higher speeds than before, advantage of the improved properties could not be taken until the machines themselves had been completely redesigned to allow of such high speeds without undue vibration; and in fact the introduction of carbide tools has meant a revolution in the machine tool industry, much plant intended for large outputs being rendered obsolete.

Three examples may be given of the substitution of an entirely new material for one of which the supplies have been found to be inadequate or too costly. Platinum, a metal of very local occurrence, has been largely replaced for chemical purposes, fused silica taking its place in the concentration of sulphuric acid, and iron oxide in various catalytic processes. On a larger scale, Chile nitrate, a product formed under quite exceptional climatic conditions and almost unique, is no longer indispensable as a fertilizer, the nitrogen compounds required for agriculture and explosives being obtained synthetically from the air. The third example is the introduction of plasties, resin-like substances which may be given the most varied properties. For many purposes they replace metals, and when reinforced by textile material or paper have a strength comparable with that of a metal. Transparent varieties replace glass and are far less brittle; other types take the place of porcelain and earthenware. The manufacture of plastics is one of the rapidly growing industries, and the uses of these new materials are continually being multiplied.

It must be realized that even such substitutions as these do not necessarily lessen our dependence on mineral resources, although the relative importance of different deposits may be altered. Nitrogen com. pounds are obtained by the use of electric power, which in some countries is derived from water, but in some of the most highly industrialized countries 
has to come from the combustion of coal. Many of the plastics are also derived from coal or petroleum, but being organic compounds, there is always the possibility of producing them from vegetable matter, as for example through the production of alcohol by fermentation and its conversion into more complex compounds. Such a procedure would be in line with the policy of depending on current revenue, derived from plants, rather than drawing unnecessarily on mineral capital, which once exhausted is not replaced.

Much might be said of means of economizing metals : the use of structures built up by welding, in place of heavy castings ; the combination of concrete with steel in buildings and bridges ; the saving of valuable metals by employing them as thin coatings on mild steel in chemical plant, and so on; but space does not permit. As new materials come into use and new techniques are developed, while at the same time the known reserves of some indispensable metals are being depleted, it becomes clear that the efficient use of the world's mineral resources demands systematic planning. First of all, a far more thorough world survey is needed, gathering together the information collected by prospectors in the interest of large industrial corporations as well as by the various national surveys. Such a survey would be the essential basis of any system of international control of mineral resources.

\section{GROWING-POINTS IN THE STUDY OF GROWTH AND DEVELOPMENT}

\author{
By Dr. JOSEPH NEEDHAM, F.R.S.
}

$\mathrm{E}$ XPERIMENTAL morphology is a subject which has long suffered from the scattered nature of its publication mechanisms. The great series of the Archiv. f. Entwicklungsmechanik was at one time central, but is now, alas! no longer available, and though the American anatomical journals long offered a home for such studies, much of the work appeared in the proceedings of learned societies not always very accessible (for example, the Finnish contributions). Work on the borderlines of biochemistry and morphology, in particular, was widely scattered. Hence the need for some periodical publications of the regular conference type, to do for experimental morphology what the Cold Spring Harbor Symposia had begun to do so well for general physiology. The symposia now under review* are often referred to by the name of "Growth Supplements" ; the correct description enshrining an auspicious pun. They will certainly stimulate the growth of our knowledge about growth and differentiation.

- First Symposium on Development and Growth, 1939; North Truro, Mass., ed. N. J. Berrill; contributions by W. H. Lewis, $P$. W Gregory, C. Stern, C. H. Waddington, J. Needham, O. Glaser, O. E. chotté, E. W. Sinott, J. H. Woodger; Supplement to Growth, vol. 3. Second Symposium on Development and Growth, 1940 ; Salisbury Cove, Maine; contributions by 0 . L. Sponsler, R. Schœnheimer, $H$. reundlich, G. S. Avery, D. M. Whitaker, A. B. Dawson, V. C. Twitty H. S. N. Greene, and F.'S. C. Northrop. Supplement to Growth, vol. 4 .' Third Symposium on Development and Growth, 1941 ; Hanover, New Hampshire; contributions by F. O. Schmitt, v. Tartar, K. B. Raper, A. F. Blakeslee, N. J. Berrill, A. H. Hersh, L. C. Dunn, and P. Weiss. Supplement to Growth, vol. 5 .

All the Growth Symposia are obtainable as follows: by members of the Society for the Study of Development and Growth on applica-
tion to Dr. J. W. Wilson, Biology Department, Brown University, tion to Dr. J. W. Wilson, Biology Department, Brown University, Providence, R.I., U.S.A.; by non-members on application to the Editors of Growth, Dairy Building, Cornell University, Ithaca, N.Y.
U.S.A. Prices : for members, vol. 1 , 1 dollar, vols. 2 and 3,2 dollars for non-members, vol. 1,2 dollars; vols. 2 and 3,3 dollars.
I had the good fortune to be present at the first two of these symposia. North Truro is a village lost among the sandy hills of Cape Cod, and there, in the spacious village schoolroom, under blue skies but with the shadow of war hanging over us, some hundred members met to discuss problems of experimental morphology. The proceedings were opened by an excellent account of the contributions of the explantation method by the veteran investigator, Warren N. Lewis. It is often forgotten that the discovery of the inductive action of the eye-cup on the presumptive lens tissue was discovered by him and Hans Spemann independently about the turn of the century, and that seven years later he narrowly missed finding that inductive action of the primary organizer itself which had to await the classical paper of Spemann and Hilde Mangold in 1924. Much of the rest of the North Truro symposium was, in fact, occupied by discussions of the present state of the organizer problem, in which valuable contributions were made by Paul Weiss. Arising out of Oscar Schotté's paper, considerable attention was given to the re-acquisition of competence by tissues undergoing regeneration, and the term 'recuperation' was proposed and adopted for this phenomenon. Curt Stern's paper was also very stimulating on the relation of genes and inductors. As regards growth proper, there was a good summary of the work on glutathione as a genetically controlled diffusible inductor working on body-size, by P. W. Gregory; and E. W. Sinott summarized his interesting investigations on the morphogenetic fields of the fruits of the Cucurbitaceæ.

The second symposium took place in the following summer at Salisbury Cove, Maine, and as there was not sufficient accommodation at the Marine Biological Station there for the meetings, we were kindly given the use of a charming wooden chapel in New England style, to which the members of the symposium were summoned by the ringing of the bell by the chairman. Here several brilliant summaries were given, particularly those by Douglas Whitaker on the mutual interactions of cells as exhibited in the early development of Fucus "eggs"; and by V. C. Twitty on the size-controlling factors in amphibian development, in which the complex questions of self-wise and neighbour-wise phenomena in growth of parts after transplantation and in physiological behaviour such as cardiac rhythm and pigment formation were lucidly described. $\mathbf{H}$. Greene's account of the pathology of development, genetically produced abnormalities, etc., will also be found of much interest. For the biochemist, there was a brilliant account by the great physical chemist Freundlich (then at Wisconsin) of the colloid chemistry of development and growth, paying special attention to liquid crystalline phases in living cells, birefringence, importance of anisometric protein particles, etc. This article has also the melancholy interest of being the last which Herbert Freundlich wrote before his death. There was also an animated discussion of protein structure by O. L. Sponsler, well known as one of the earliest workers to apply the methods of X-ray crystallography to living structures (plant cell-walls).

The third symposium opened with an exceptionally important article by F. O. Schmitt on "protein patterns" in cells. This centred around the question of what it is exactly which happens to the cells of the presumptive neural tube in the embryo when, under the influence of the primary inductor, they 